\title{
Corrigendum: Internet Blogs, Polar Bears, and Climate-Change Denial by Proxy
}

\author{
JEFFREY A. HARVEY, DAPHNE VAN DEN BERG, JACINTHA ELLERS, REMKO KAMPEN, THOMAS W. CROWTHER, \\ PETER ROESSINGH, BART VERHEGGEN, RASCHA J. M. NUIJTEN, ERIC POST, STEPHAN LEWANDOWSKY, \\ IAN STIRLING, MEENA BALGOPAL, STEVEN C. AMSTRUP, AND MICHAEL E. MANN
}

This paper has been corrected online and in print in order to clarify Dr. Crockford's scientific expertise and financial links in relation to the arguments made in the paper (BioScience 68: 281-287). The corrected text is as follows:

First change: Notably, as of this writing, Crockford has neither conducted any original research nor published any articles in the peer-reviewed literature on the effects of sea ice on the population dynamics of polar bears.

Second change: Some of the most prominent AGW deniers, including Crockford, are linked with or receive support from organizations that downplay AGW (e.g., Dr. Crockford has previously been paid for report writing by the Heartland Institute).

The authors apologize for any confusion.

Jeffrey A. Harvey (j.jharvey@nioo.knaw.nl) is affiliated with the Department of Terrestrial Ecology at the Netherlands Institute of Ecology, in Wageningen. JAH, Daphne van den Berg, and Jacintha Ellers are with the Department of Ecological Sciences-Animal Ecology at the VU University Amsterdam, in The Netherlands. Remko Kampen works in Gouda, the Netherlands. Thomas, W. Crowther is with the Department of Terrestrial Ecology at the Netherlands Institute of Ecology, in Wageningen, and with the Institute of Integrative Biology, in Zürich, Switzerland. Peter Roessingh is with the Institute for Biodiversity and Ecosystem Dynamics at the University of Amsterdam, in The Netherlands. Bart Verheggen is affiliated with Amsterdam University College, in The Netherlands. Rascha J. M. Nuijten is with the Department of Animal Ecology at Netherlands Institute of Ecology, in Wageningen. Eric Post is affiliated with the Department of Wildlife, Fish, and Conservation Biology at the University of California, Davis. Stephan Lewandowsky is with the School of Experimental Psychology and Cabot Institute at the University of Bristol, in the United Kingdom, and with CSIRO Oceans and Atmosphere, in Hobart, Tasmania, Australia. Ian Stirling is affiliated with the Wildlife Research Division of Environment and Climate Change Canada, and with the Department of Biological Sciences at the University of Alberta, in Edmonton, Canada. Meena Balgopal is with the Department of Biology at Colorado State University, in Fort Collins. Steven C. Amstrup is affiliated with Polar Bears International, in Bozeman, Montana, and with the Department of Zoology and Physiology at the University of Wyoming, in Laramie. Michael E. Mann is affiliated with the Department of Meteorology and Atmospheric Science at Pennsylvania State University, in University Park.

doi: 10.1093/biosci/biy033 